\title{
A gestão da UEIIA/UFSM em tempos de Covid-I 9: escuta, diálogo e rupturas
}

\author{
Management of UEIIA/UFSM in Covid- 19 times: \\ listening, dialogue and rupture
}

\section{Gestión del UEIIA/UFSM en tiempos de Covid-I 9: escucha, diálogo y rupturas}

\author{
Viviane Ache Cancian' \\ https://orcid.org/0000-0002-007I-763 \\ Juliana Goelzer ${ }^{2}$ \\ https://orcid.org/0000-0003-2066-1589
}

\begin{abstract}
Resumo: Neste texto o objetivo é apresentar algumas das ações que temos realizado, enquanto equipe de gestão, no contexto da Unidade de Educação Infantil Ipê Amarelo (UEIIA/UFSM/RS), frente ao distanciamento social provocado pela Covid-19. Tais ações passam por discussões, análises e proposições do que é possível nesse momento, com os sujeitos que temos, através de um olhar atento, com escuta sensível, envolvimento e diálogo constante entre todos, garantindo a identidade da UEIIA. Tomando por base a legislação nacional para a Educação Infantil (BRASIL, 2009; CAMPOS; ROSEMBERG, 2009) e referenciais na área da Educação Infantil que partem de uma perspectiva de escuta e acolhimento (RINALDI, 20I4; STACCIOLI, 20I3), consideramos que este é um momento de abertura para novas formas de convívio, de interlocução, de intensificação das relações, com o futuro possível, uma outra cultura institucional.
\end{abstract}

Palavras-chave: Gestão. Educação Infantil. Covid-19.

Abstract: This paper aims to show some of our actions as a management team in the Unit of Early Childhood Education Ipê Amarelo - UEIIA/UFSM (RS) - concerning the social distancing to help prevent the spread of Covid-19. These actions include discussing, analysing and proposing what is possible to do in this moment with actual subjects through a closer look, sensitive listening, participation, and constant dialogue with all, ensuring UEIIA's identity. Drawing on the national law of Early Childhood Education (BRASIL, 2009; CAMPOS; ROSEMBERG, 2009) and reference frames in the field of Early Childhood Education based on listening and

\footnotetext{
I Doutora em Educação, professora do Departamento de Metodologia de Ensino/CE/UFSM. Diretora da Unidade de Educação Infantil Ipê Amarelo/UFSM. Grupo de Pesquisa Estudos sobre Infância: Políticas Públicas, Currículo, Práticas Pedagógicas e Formação Docente/UFSM. E-mail: viviane.cancian@ufsm.br

2 Doutora em Educação, professora do Departamento de Metodologia de Ensino/CE/UFSM. Diretora da Unidade de Educação Infantil Ipê Amarelo/UFSM. Grupo de Pesquisa Estudos sobre Infância: Políticas Públicas, Currículo, Práticas Pedagógicas e Formação Docente/UFSM. E-mail: viviane.cancian@ufsm.br
}

Olhar de professor, Ponta Grossa, v. 24, p. I-8, e-16293.033, 2021.

Disponível em <https://revistas2.uepg.br/index.php/olhardeprofessor> 
welcoming (RINALDI, 20I4; STACCIOLI, 20I3), we have considered that this is the time for new ways of social life, dialogue, enhance of relations with a possible future, a new institutional culture.

Keywords: Management. Early Childhood Education. Covid-19.

Resumen: Este texto tiene como objetivo presentar algunas acciones que tenemos realizado como equipo de gestión en la Unidad de Educación Infantil Ipê Amarelo - UEIIA/UFSM (RS) - con respecto al distanciamiento social provocado per la Covid-19. Estas acciones pasan per las discusiones, análisis y proposición de lo que es posible en ese momento, con los sujetos que tenemos a través de una mirada atenta, con una escucha sensible, envolvimiento y diálogo constante entre todos, garantizando la identidad de la UEIIA. Haciendo uso de la legislación nacional para la Educación Infantil (BRASIL, 2009; CAMPOS; ROSEMBERG, 2009) y referencias en el área de la Educación Infantil que parten de una perspectiva de escucha y acogida (RINALDI, 20I4; STACCIOLI, 2013), consideramos que este es un momento de apertura para nuevas formas de convivencia, de interlocución, de intensificación de las relaciones con el futuro posible, otra cultura institucional.

Palabras-clave: Gestión. Educación Infantil. Covid-19.

\section{Introdução: a pandemia, a educação infantil e a UEIIA}

A pandemia mundial causada pela Covid-19 tem exigido de todas as pessoas uma reinvenção de seus modos de ser e estar no e com o mundo e com os outros. Na educação, muitos têm sido os desafios nesse processo de reinvenção, e na educação infantil têm exigido das equipes das instituições um diálogo constante entre si e uma escuta sensível das crianças e famílias; fazem-se necessários para tornar possível a continuidade do vínculo e o fortalecimento das relações em um momento em que por ora necessita ser suspensa a presença física, tão necessária aos bebês, crianças bem pequenas e pequenas.

Desse modo, reinventar-se, no contexto da educação infantil, tem apresentado desafios constantes e exigido rupturas educacionais e a consequente reinvenção das práticas educativas. $\mathrm{Na}$ Unidade de Educação Infantil Ipê Amarelo (UEIIA) temos buscado enfrentar esses desafios em um processo de escuta e diálogo constante com a equipe, crianças, famílias e comunidade, buscando reinventar uma proposta pedagógica de escuta já praticada ${ }^{3}$ e que constantemente é reavaliada.

A UEIIA é uma Unidade da Universidade Federal de Santa Maria (UFSM/RS) que está vinculada administrativamente à Coordenadoria de Ensino Básico, Técnico e Tecnológico (CEBTT) e pedagogicamente ao Centro de Educação (CE). É uma Unidade que completou $3 \mathrm{I}$ anos de história e que tem acesso universal de ingresso, o que possibilita que crianças das mais diversas classes sociais, raças, etnias e culturas convivam, compartilhando saberes e ampliando seus universos culturais.

Atualmente a Unidade atende crianças de 4 meses a 5 anos e 1 I meses e tem uma proposta que busca garantir a escuta, o protagonismo e os direitos das crianças, a inclusão, o respeito às diferenças, as vivências cotidianas entre crianças de diferentes idades - especialmente nas turmas multi-idades -, o respeito à diversidade, a busca por justiça social e por novas formas de sociabilidade, rompendo com as relações de dominação etária, étnico racial e religiosa. Trata-se de

\footnotetext{
${ }^{3}$ Conforme o Projeto Político Pedagógico da Unidade de Educação Infantil Ipê Amarelo (2019).
}

Olhar de professor, Ponta Grossa, v. 24, p. I-8, e-16293.033, 2021.

Disponível em <https://revistas2.uepg.br/index.php/olhardeprofessor> 
uma construção de infância que, em diálogo com a Carta da Terra e a Agenda 2030, possa ser vivida em ambiente coletivo, respeitando as diferenças e as diferentes formas de vida no planeta ${ }^{4}$.

Busca-se, ainda, a natureza da UEIIA na UFSM: exercer a função acadêmica de indissociabilidade do ensino, da pesquisa e da extensão. Temos o privilégio de conviver diariamente com a formação inicial e continuada de acadêmicos de diferentes unidades de ensino, de diferentes cursos da UFSM e de outras IFES; com egressos e profissionais da educação e de outras áreas; com bebês, crianças bem pequenas e pequenas. Recebemos acadêmicos para realizar observações, pesquisas, intervenções, estágios, assim como visitações de profissionais da educação e de diferentes áreas, de diferentes universidades e escolas. Esses acadêmicos aprendem no vivido a natureza e os desafios da docência e, ao sair da UEIIA, alçam voos através de concursos para fazer a diferença nas redes e sistemas de ensino, levando a docência refletida e compreendida a esses espaços e tempos de garantia de direitos das crianças.

Neste texto o objetivo é apresentar algumas das ações desse percurso que temos vivido, ações essas que passam por discussões, análises e proposições do que é possível nesse momento, com os sujeitos que temos, através de um olhar atento, com escuta sensível, envolvimento e diálogo constante entre todos, garantindo a identidade da UEIIA. Para tanto, apresentamos o contexto e os sujeitos envolvidos, as relações entre o que chamamos de diferentes segmentos, o acolhimento e a escuta das crianças e dos adultos, e a constituição da Unidade como espaço formativo nesse contexto de necessário distanciamento social provocado pela pandemia.

\section{Os desafios de compreender o contexto e todos os envolvidos}

Em um primeiro momento a gestão buscou compreender a totalidade do vivido, o lugar e o sentido de existência de cada um, o respeito à subjetividade, à singularidade e, ao mesmo tempo, o desafio de garantir o coletivo em um momento de distanciamento. Tínhamos uma única certeza, a de que vivíamos uma excepcionalidade, uma situação global, peculiar e que estávamos juntos em uma mesma causa, a do cuidado com a vida, com a saúde coletiva, um momento de poucas certezas e de muitas incertezas. Buscou-se conhecer mais de perto a realidade dos sujeitos que fazem parte da comunidade interna da UEIIA, a saber, servidores federais, terceirizados (professores, auxiliares de limpeza, cozinha, lactário, lavanderia), bolsistas, alunos da graduação e pós-graduação, e organizamonos de modo a auxiliar financeiramente a quem precisava.

\footnotetext{
4 Para mais informações, ver: CANCIAN, Viviane Ache; GOELZER, Juliana; BELING, Vivian Jamile (Orgs.). Práticas formativas e pedagógicas na Unidade de Educação Infantil Ipê Amarelo-UFSM: narrativas docentes. Santa Maria: Colégio Técnico Industrial de Santa Maria, Unidade de Educação Infantil Ipê Amarelo-UFSM, 20 I9.
}

Olhar de professor, Ponta Grossa, v. 24, p. I-8, e-I6293.033, 2021.

Disponível em <https://revistas2.uepg.br/index.php/olhardeprofessor> 
No começo de abril decidimos planejar ações, registrar, analisar e avaliar constantemente o processo, os desafios e potencialidades do acolhimento a todos. Passamos a utilizar o WhatsApp, a página do Facebook e o site da Unidade como espaço de comunicação com a comunidade, com a publicização das ações da UEIIA e da UFSM no combate à Covid-19. Organizamos uma agenda semanal para encontros de toda a equipe, da equipe gestora, dela com a gestão da UFSM e de grupos de trabalho específicos.

Tendo em vista que "Para proporcionar um ambiente respeitoso (aos adultos e às crianças), é necessário prever, projetar, organizar, realizar, manter e renovar..." (STACCIOLI, 20I3, p. 5), enviamos formulário com o objetivo de conhecer as demandas das famílias e depois realizamos uma primeira reunião com elas buscando retomar principalmente o diálogo referente aos direitos das crianças, reforçando que a legislação (BRASIL, 2009; CAMPOS, ROSEMBERG, 2009) e a caminhada da área da Educação Infantil eram contrárias ao caráter instrucional. A UEIIA, como garantia de sua proposta, portanto, não enviaria para a casa das famílias "atividades" como folhinhas para pintar e com exercícios a fazer, não indicaria listas de atividades, uma vez que não tem proposta de reprodução, mas sim de criação, de produção de culturas, com centralidade nas relações que estabelecemos com crianças e adultos, professores, bolsistas, famílias, servidores, terceirizados, que compõem o que chamamos de diferentes segmentos.

Destacamos que a Educação Infantil é ofertada em espaços coletivos, trazendo a riqueza da diversidade, das relações que estabelecemos com as experiências e vivências de todos, interagindo com diferentes culturas e que, portanto, entendemos que a escola da infância só faz sentido nessas condições, que o distanciamento social trazia para a UEIIA o desafio de compreender as relações do privado, da casa, de cada família, de cada criança, respeitando as fronteiras, o que é da família e o que é da escola, que o âmbito privado é diferente do caráter coletivo das instituições educacionais. Compreender essa particularidade de cada segmento não nos permitia invadir os lares, negar que cada família tivesse a sua organização, o seu tempo, as suas necessidades, a sua autonomia, não cabendo à escola e ao professor planejar e dizer o que cada família deveria fazer.

Sugerimos que, frente a isso, as famílias pudessem aproveitar o distanciamento social para fortalecer suas relações com seus filhos, dedicando mais tempo à vivência com eles, pois muitos pais, em função da demanda do trabalho, tinham pouco tempo disponível para ficar com os filhos. Ressaltamos que esse poderia ser um tempo para se pensar nas relações que se estabelecem nos lares, os valores, as prioridades, o lugar das crianças, clareando qual educação queremos para elas, para os processos formativos de cada um e, em especial, para o futuro do planeta. Um tempo de vivências, de riquezas, de laços fortalecidos, oportunidade singular para exercitar a escuta e estar mais próximos das vivências do dia a dia. Marcamos isso e reafirmamos que nós e cada família nos

Olhar de professor, Ponta Grossa, v. 24, p. I-8, e-16293.033, 2021.

Disponível em <https://revistas2.uepg.br/index.php/olhardeprofessor> 
reinventaríamos, voltando diferente após o vivido e com um compromisso com o coletivo, com cada criança em especial.

Nesse sentido, o desafio principal da gestão era manter e fortalecer o vínculo com todos os segmentos, com esse coletivo que faz o dia a dia da Educação Infantil na UEIIA, realizando uma escuta atenta a todos, proporcionando momentos de diálogos para pensar em uma organização, em um planejamento que garantisse a escuta das crianças, que pensasse nas singularidades e nas condições de cada uma delas, em quem estaria junto a elas, nas condições psicológicas, emocionais do adulto, na disponibilidade. Para Rinaldi (2012, p. 43), uma Pedagogia da escuta, do pensamento "[...] envolve uma relação ética de abertura ao Outro, tentando escutar ○ Outro em sua própria posição e experiência, sem tratar o Outro como igual”.

Professores e bolsistas realizaram uma escuta atenta do grupo de crianças e famílias de cada turma e, com o apoio da equipe pedagógica e multiprofissional, pensaram em propostas com o grupo. A partir dessa escuta foram organizados momentos de encontros virtuais individuais em pequenos grupos e coletivos com as crianças, realizados semanalmente; foram organizadas e compartilhadas propostas de contação de histórias, de compartilhamento de receitas, experiências, brincadeiras e outras vivências diversas através de lives, folhetos, cartas, vídeos, áudios e documentação pedagógica.

O tempo e o espaço de cada criança e família são respeitados em todas as propostas, todos são convidados a participar e as famílias são orientadas a escutar as crianças com relação ao desejo de participação delas. Diferentes encontros são marcados entre a turma, dos quais participa quem tenha disponibilidade e interesse, e reuniões individuais com as famílias são agendadas conforme sugestão da Unidade ou demanda da própria família.

A equipe de Atendimento Educacional Especializado (AEE) juntamente com a psicóloga da Unidade procuram dar o suporte necessário às famílias e crianças, público-alvo do AEE na Unidade. Esses profissionais, em conjunto com as professoras das turmas, realizam reuniões com as famílias dessas crianças buscando ouvi-las e orientá-las. A equipe de AEE também mantém contato com as crianças incluídas que eram atendidas no ano anterior e que ingressaram no Ensino Fundamental este ano, colocando-se à disposição para apoiar essas crianças e suas famílias em suas necessidades, garantindo assim o acompanhamento delas no processo de transição da Educação Infantil para o primeiro ano do ensino fundamental.

Além dessas propostas organizadas no âmbito das turmas, realizamos outras de modo coletivo, tais como a comemoração dos 31 anos da Unidade - através de um encontro virtual com show musical junto à comunidade -, teatro, vídeos produzidos pela equipe com todas as pessoas que

Olhar de professor, Ponta Grossa, v. 24, p. I-8, e-16293.033, 2021.

Disponível em <https://revistas2.uepg.br/index.php/olhardeprofessor> 
atuam na Unidade desde a recepção, com todos os adultos deixando sua mensagem às crianças, encontros e reuniões virtuais com as famílias.

Buscando apoiar a comunidade em geral nesse momento de crise, a Associação de Pais e Mestres (APM) organizou uma Campanha Solidária para arrecadar doações às famílias da UEIIA e de bairros próximos. Essa ação tem sido contínua e todos os meses a APM arrecada doações, faz o levantamento de quem mais as necessita e as leva a essas famílias/instituições.

A equipe de gestão, ao longo desse tempo, tem se preocupado constantemente com a escuta da equipe que está à frente desse processo, compreendendo que eles/elas também continuam enfrentando desafios diários em suas casas, com suas famílias, filhos, e que, por isso, nem sempre conseguem atender a todas as demandas impostas pelo momento, sempre buscando garantir 0 suporte necessário à medida que é identificado.

\section{Os desafios da unidade como espaço formativo frente a esse contexto}

Ao longo desse período de pandemia, a UEIIA também não deixou de lado seu compromisso com a formação inicial e continuada de professores de educação básica. Foi organizado um curso online de formação na Plataforma Moodle da UFSM, com temáticas levantadas pela equipe e organizada uma agenda semanal de encontros de formação para a equipe de professores, bolsistas e demais profissionais da Unidade. Além dessa organização interna, tendo em vista o compromisso da Unidade com a extensão, com a produção e socialização do conhecimento, a equipe promove webinários mensais e é parceira de lives organizadas pela Pró-reitoria de Extensão da UFSM e de encontros organizados pelo Núcleo de Estudos e Pesquisa em Educação Infantil (NEPEI), Fórum da Região Central e Fórum Gaúcho de Educação Infantil (FGEI), da Secretaria Municipal de Educação de Santa Maria/RS (SMED), da Associação Nacional das Unidades Universitárias Federais de Educação Infantil (ANUUFEI) e Conselho Nacional dos Dirigentes das Escolas de Educação Básica e das Instituições Federais de Ensino Superior (CONDICAP).

Compreendendo o lugar das Unidades Universitárias de Educação Infantil no país, a equipe da gestão coloca o desafio do diálogo com as redes e sistemas, com a sociedade, com a proximidade, com uma escuta que valoriza experiências outras, lugares e contextos diferentes. Importante clarear que essas ações e desafios que se colocam hoje com a pandemia, já faziam parte de uma prática refletida constantemente, com discussões teórico-práticas. Nesse sentido, por perceber que a área da Educação Infantil tem avançado muito nos últimos anos, mas que mesmo assim não chegou a todos por inúmeros motivos - e um deles é a falta de um plano de carreira que garanta horário de planejamento e formação -, estamos organizando um diálogo online que transcende os muros da 
UFSM, por entendermos que nesse momento conseguimos chegar nos professores, nas escolas, no vivido.

Um dos momentos desse diálogo que transcendeu a discussão com o local e o regional foi a comemoração dos 31 anos da Unidade, um webinário com a participação das Professoras Viviane Ache Cancian, Maria Carmem Barbosa, Rita Coelho, Zilma de Oliveira, Sílvia Helena Cruz e Paulo Sérgio Fochi, cuja temática foi a Base Nacional Comum Curricular (BNCC) e os direitos das crianças. Nesses momentos nos colocamos no lugar de abertura para o diálogo, um lugar de encontro, de afirmação do espaço público e de valorização deste como tal.

Esses encontros que realizamos trazem uma gama de diversidades e revelam um caminho que se mostra de mão dupla de uma universidade que, ao dialogar com as redes e sistemas, com outras instituições, é convidada a se repensar a todo momento e não somente em tempos de distanciamento social. Apesar das incertezas e desafios, muitas são as possibilidades de consolidar a Unidade como espaço formativo.

\section{Rupturas e abertura ao novo}

Compreendemos que, ao buscar intensificar as relações, o fortalecimento desses vínculos tem sido possível especialmente porque essa relação de proximidade com as famílias, com as crianças, com todos os segmentos, já existia na Unidade. Nesse espaço-tempo de distanciamento se consolidaram/consolidam outros laços, afetos, escutas sensíveis, possibilidades outras, acolhimento de todos, que nos permitem compreender que estamos em processo, que esse vivido com base na escuta continua sendo prioritário no enfrentamento da Covid-19, nesta grave crise que envolve a educação, setores da saúde, da economia, do trabalho, dos direitos humanos em nosso país e que atinge a cada pessoa/família/grupo de forma muito singular e que, portanto, necessita de uma política intersetorial.

Cabe, como gestão, a consonância com princípios, a co-responsabilidade com o planeta, com suas diversas formas de vida, com a saúde coletiva. Essa co-responsabilidade ética, política e social legitima a importância do Outro, do diálogo entre todos, da solidariedade, do fortalecimento dos laços (escola, família e comunidade) em prol da saúde (física e psicológica) de nossas crianças e de toda a comunidade interna e externa.

É um momento de rupturas de uma cultura institucional, escolar, que agora precisa estar aberta para o novo, para novas formas de convívio, de interlocução de saberes, de intensificação das relações, de planejamento, registro, análise, interpretação, avaliações constantes do processo, dos desafios, das dificuldades de todas as ordens, do estrutural, do humano, e das potencialidades numa

Olhar de professor, Ponta Grossa, v. 24, p. I-8, e-16293.033, 2021.

Disponível em <https://revistas2.uepg.br/index.php/olhardeprofessor> 
projeção de uma nova instituição de educação infantil, numa perspectiva de reconstrução, pensando o presente e o passado com vistas a outro futuro, o futuro possível.

\section{Referências bibliográficas}

BRASIL. Ministério da Educação. Conselho Nacional de Educação. Câmara da Educação Básica. Revisão das Diretrizes Curriculares Nacionais para a Educação Infantil. Parecer CNE/CEB N²0/2009. Brasília: DF, 2009.

CANCIAN, V. A.; GOELZER, J.; BELING, V. J. (Orgs.). Práticas formativas e pedagógicas na Unidade de Educação Infantil Ipê Amarelo-UFSM: narrativas docentes. Santa Maria: Colégio Técnico Industrial de Santa Maria, Unidade de Educação Infantil Ipê Amarelo-UFSM, 2019.

CAMPOS, M. M.; ROSEMBERG, F. Critérios para um atendimento em creches que respeite os direitos fundamentais das crianças. 6.ed. Brasília: MEC, SEB, 2009.

RINALDI, C. Diálogos com Reggio Emília: escutar, investigar e aprender. Trad. Vania Cury. São Paulo: Paz e Terra, 2012.

STACCIOLI, G. Diário de acolhimento na escola da infância. Campinas, SP: Autores Associados, 2013.

UNIVersidade federal de SANTA MARIA. Projeto Político Pedagógico da Unidade de Educação Infantil Ipê Amarelo. Santa Maria: 2019. II 4 p.

Recebido em: 02 de julho de 2020

Versão corrigida recebida em: 09 de outubro de 2020.

Aceito em: 09 de outubro de 2020.

Publicado online em: 09 de abril de 2021.

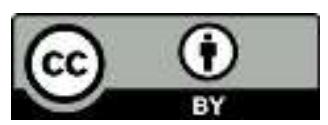

Olhar de professor, Ponta Grossa, v. 24, p. I-8, e-16293.033, 2021.

Disponível em <https://revistas2.uepg.br/index.php/olhardeprofessor> 